Nataly Cancino Cabello

Universidad de Sevilla

\title{
Causalidad y temporalidad: el caso de cuando en ensayos chilenos del siglo $X X$
}

Palabras clave: causalidad, consecutividad, condicionalidad, temporalidad, ensayos

\section{Presentación}

Este trabajo surge de la observación de un corpus elaborado para una investigación mayor sobre las formas de expresión de la relación causa-efecto en la norma culta del español de Chile ${ }^{1}$, en el cual descubrimos la estrecha vinculación existente entre las nociones causales y temporales.

Nuestro objetivo actual es describir dicha relación a partir del análisis de una forma lingüística que participa en la expresión de ambos sentidos. Se trata de cuando. De este estudio, que se realiza desde una perspectiva semánticamente amplia, surgen algunas dudas que nos llevan a buscar respuestas en los procesos de cambio lingüístico que puedan haber participado en la coincidencia de los significados.

\section{Antecedentes teóricos}

En el abordaje de la causalidad encontramos una perspectiva que se ocupa por separado de dos tipos de construcciones (causales y consecutivas), pese a su cercanía. Incluimos en este grupo estudios como los de Gili Gaya (1970), Alarcos (1999) y Álvarez (1999). El trabajo de Montolío (2001), por otra parte, enfatiza

1 Nos referimos a Expresión de la causalidad en la norma culta del español de Chile, Tesis para optar al grado de Magíster en Lingüística por la Universidad de Playa Ancha (Valparaíso, Chile), dirigida por el Dr. Hugo Cifuentes Salinas. 
en la vinculación entre ambos tipos, por lo que incluye causa y consecuencia bajo un concepto semántico amplio de consecutividad en las lenguas.

Sin embargo, creemos que, además de su expresión formal y funcional en la lengua, la causalidad constituye una relación lógica y semántica inherente a los procesos naturales, puesto que toda causa es necesariamente anterior a su consecuencia ${ }^{2}$. De ahí se desprende la ligazón entre la causalidad y el eje temporal en que se desarrollan las acciones. Por ello, postulamos que la relación causa-efecto no es privativa de las construcciones causales y consecutivas, sino que también abarca otro tipo de estructuras, donde lo que variará será el grado o clase de vinculación entre los miembros.

Tras revisar la propuesta de Galán (1999), compartimos con la autora que el campo semántico de la causalidad abarca cinco tipos de construcciones diferenciadas de acuerdo a la relación que cada una establece entre causa y efecto:

- causales: en ellas recae el énfasis de la relación causal e indican una causa originaria que provoca un efecto. Pueden ser propias o explicativas. En las primeras se trata de la causa efectiva (No fue a clases porque está enfermo), mientras en las segundas se indican las circunstancias favorables o conocidas de una acción (No fue a clases porque sus cosas están en casa).

- condicionales: someten la causa a hipótesis, de manera que la relación causa-efecto ya no constituye un hecho real y su realización sólo es posible (Si no vas a la escuela nunca tendrás un buen trabajo).

- concesivas: niegan la relación causa-efecto, pues no se llevan a cabo las expectativas que habitualmente se esperan (Aunque estudias mucho y no faltas a clases, tienes malas notas).

- consecutivas: son aquellas con énfasis en el resultado efectivo de una acción (Está enfermo, así que no fue a clases).

- finales: también enfatizan el resultado, pero en ellas se propone un efecto buscado intencionalmente, cuya realización efectiva se desconoce (Voy al colegio para sacar buenas notas).

De acuerdo con un trabajo anterior (Cancino, 2006), incluimos en este grupo también algunos tipos de adversativas excluyentes que pueden parafrasearse por una causal explicativa, como en No fue a clases, sino que se quedó en casa, en la cual se invierte una causa posible.

2 Excepto en el caso de la concomitancia, cuando son simultáneas. No obstante, cabe la discusión sobre si esta relación es causal o solo explicita el paralelismo de las acciones que refiere. 


\section{El corpus}

El análisis se ha realizado sobre la base de un corpus compuesto por ensayos, textos en los que predomina la exposición-argumentación, pues en esta clase de escritos es en donde preferentemente se manifiestan las relaciones que nos ocupan, ya que para

presentar una serie de informaciones de manera razonable y convincente, a fin de conducir al lector a las conclusiones que interesan, es imprescindible [...] relacionar las oraciones $y$, en general, las secuencias textuales entre sí de manera que se presenten [...] las causas que conducen a las consecuencias. (Montolío, 2001: 43)

Hemos definido como fecha de realización el siglo XX para delimitar un corpus «manejable» a partir de la perspectiva que nos da el reciente pasado y que al mismo tiempo nos permita explicar sus usos a la luz de aspectos diacrónicos. Por otra parte, pensamos que es necesario describir el funcionamiento de esta relación en la norma culta del español de Chile, sobre la cual no hemos encontrado trabajos parecidos.

Nuestro corpus se compone, en total, por 35 mil palabras, 5 mil por cada autor, distribuidas en los textos de Joaquín Edwards Bello (1969), Gabriela Mistral (1978), Pablo Neruda (2000), Pedro Prado (1981), Gonzalo Rojas (1998), Manuel Rojas (1960) y Volodia Teitelboim (1969).

\section{Análisis}

Tradicionalmente, el empleo de la forma cuando ha sido descrito como temporal en la tradición gramatical. No obstante, hemos detectado en el corpus un uso que manifiesta la relación causal entre dos juicios. Son estos casos los que nos ocupan en el presente apartado.

Cuando es el resultado de la unión del latín quam y la enclítica -do (Bassols, 1981: 343). Es categorizada por el DRAE (2001) como conjunción, adverbio o preposición, dependiendo de su uso. De estas clasificaciones, la de conjunción de tiempo es la que nos interesa, siendo su significado: 'En el tiempo, en el punto, en la ocasión en que. Me compadecerás cuando sepas mis desventuras. Ven a buscarme cuando sean las diez'.

De los dos ejemplos, el segundo es netamente temporal, es decir, los hechos se relacionan entre sí de acuerdo con el sentido de la sucesión de uno y 
otro. En cambio, en el primero, podemos averiguar la existencia de un valor adicional: el conocimiento de las desventuras conduce a la compasión, por lo que es posible vincular ambos juicios ya no solo por la relación temporal, sino también porque un hecho funciona como causa efectiva de su consecuente. Puede parafrasearse de la siguiente manera en una construcción causal: Me compadecerás porque sabrás mis desventuras. O bien, en una consecutiva: Sabrás mis desventuras, así que me compadecerás. Podríamos incluso incluir el parafraseo con una final: Te contaré mis desventuras, para que me compadezcas, una condicional: $S i$ te cuento mis desventuras, me compadecerás, o una concesiva: Aunque te cuente mis desventuras, no me compadecerás. Como vemos, este ejemplo contiene un cruce de sentidos entre la temporalidad y el amplio campo semántico de la causalidad.

Esta misma vinculación es la que se presenta en nuestro corpus, en el que la forma cuando expresa tres relaciones: causa, consecuencia y condición.

\section{1}

En el primer caso, es usada en construcciones causales propias, donde manifiesta un sentido temporal implícito.

Se sorprende cuando le digo que conozco poco los libros de Salvador de Madariaga, el ilustre español con quien la América no se ha puesto todavía en contacto crítico agudo, sugerente poeta y pensador sólido. (Mistral, 1978: 24)

Otro quiso bajarme del caballo cuando se publicó mi primer libro del 48 . (G. Rojas, 1998: 20)

Llegó a su punto cenital cuando, después de acordados los términos de un cese de fuego, ordenó los bombardeos más cruentos, más destructores y más cobardes en la historia del mundo. (Neruda, 2000: 112)

Pensamos que en el siguiente caso se manifiesta tan claramente la simultaneidad de las acciones descritas que no podemos evitar pensar en la concomitancia, en cuanto la consecutividad es inmediata y necesaria entre ambos juicios:

Tal se me aparece a mí Prado cuando pienso en él e intento representar su fisonomía mental y su actitud literaria. (M. Rojas, 1960: 18)

La RAE (2009), en su última Gramática, identifica casos como los de nuestros ejemplos y señala que «De la interacción del valor temporal que es característico de las cláusulas introducidas por cuando con la cláusula principal pueden 
derivarse efectos interpretativos que lleven a adoptar valores propios de otras subordinadas, como las condicionales o las causales» (RAE, 2009: 1614). Es el caso de las del tipo Cuando tú te fuiste, yo me sentí muy sola, en las que a la vez que se expresa tiempo, se sugiere la causa.

Para Bartol (1988: 165-166), el uso causal de la conjunción temporal cuando es muy frecuente en textos medievales y Menéndez Pidal ([1908] 1944) lo identifica en el Cantar del Mio Cid. Ya en latín, la forma quando se usa como indicador de causa conocida, a partir de lo cual sus resultados españoles podrían haber tomado dicho valor. Es más, según Mosteiro (1999), en la época clásica apenas se usa como temporal, pues no aparece ni en César, ni en Salustio, ni en Tito Livio, ni en Tácito. También recuerda que esta no es la única forma en donde concurren ambos valores. De ese modo, estudia el paso de la noción temporal originaria de post al sentido causal que en la actualidad tiene su resultado pues con valor explicativo.

Asimismo, se refiere a como, que en el latino quomodo sufre una extensión de funciones, adoptando los sentidos temporal, causal y final. Según MeyerLübke (1972), el paso de como al valor causal se habría producido en el contenido temporal que habría obtenido en el latín bajo, pero Cuervo (19921994) y Ridruejo (1981) lo vinculan directamente con el comparativo. Para Goethals (2002: 105), la baja frecuencia documentada del como causal en español antiguo no permite decantarse por ninguna de las dos posturas. No obstante esta discrepancia, lo importante es que en la discusión sobre el cambio de esta forma se ha introducido la idea de que la consecutividad proviene de la temporalidad, lo que nos entrega otro dato que sustenta nuestro supuesto de la cercanía semántica entre ambas nociones.

Es más, Goethals (2002: 105) indica que el uso temporal de esta forma se halla en el sentido modal: «el marco concomitante propio del sentido modalcomparativo es la base en la cual se fundamenta la relación temporal de simultaneidad».

Bartol (1988) señala que este paso del valor temporal al causal también está presente en los usos medievales de ya que, después que, desque (deque). A su juicio, este deslizamiento de sentidos corresponde a un «fenómeno semántico general que puede aparecer en la mayoría de las lenguas» (Bartol, 1988: 165). Debido a esto puede explicarse, dice, como un hecho interno propio de la modificabilidad del lenguaje, sin que sea necesario para ello acudir a factores externos, pero no excluye la idea de que este cruce de valores se produzca por 
el uso de la conjunción latina. Mosteiro (1999) se inclina a pensar que su uso causal en latín contribuye al empleo con este sentido en los primeros textos en romance, aunque en la Edad Media no se haya deslindado de lo temporal.

Para Lakoff y Johnson (1991), la relación de causación ${ }^{3}$ es un concepto frecuentemente utilizado por las personas para la organización de las realidades físicas y culturales. Señalan que se trata de «un todo que los seres humanos encontramos más básico que sus partes» (Lakoff y Johnson, 1991: 110): a lo largo de la vida, el conjunto de acciones que se produce es más importante que la realización individual de cada una, puesto que es la recurrencia lo que permite la emergencia de la causación como categoría prototípica. Se refieren los autores principalmente a hechos físicos y ejemplifican con un caso expuesto por Piaget sobre el aprendizaje de este fenómeno en niños: cuando insistentemente tiran algo al suelo están en un proceso de aprendizaje de este fenómeno mediante la manipulación. Debido a que el principio de causa está muy interiorizado en las personas, a que su aplicación es estable y a que emerge de la experiencia cotidiana, su uso se extiende a la aplicación de los conceptos metafóricos, como el del cambio de estado (por ejemplo, Hice un avión de una boja de papel de periódico).

Ahora bien, todo cambio, todo proceso se desarrolla en el eje temporal, en donde se sitúa la sucesión de acciones, por lo que ambas nociones, tiempo y causa, se vinculan conceptualmente, conformando una de las relaciones más presente en el pensamiento de las personas y con una alta frecuencia en la lengua. No obstante, a dicha unión aún no se le da el tratamiento especializado adecuado.

Si sumamos esta explicación a las anteriormente planteadas, tenemos que esta relación lógica y semántica entre causalidad y temporalidad explica tanto los usos latinos de quando, como los actuales.

3 Según los autores, las propiedades de la causación son: el agente tiene como objetivo un cambio de estado en el paciente, el cambio de estado es físico, el agente tiene un plan para cumplir su objetivo, el plan exige que el agente use un programa motor, el agente controla ese programa motor, el agente es primariamente responsable de llevar a cabo su plan, el agente es la fuente de la energía (dirige sus energías hacia el paciente) y el paciente es el objetivo de la energía (el cambio en él se debe a una energía exterior), el agente toca al paciente con su cuerpo o con un instrumento (se produce una coincidencia espacio-temporal entre la acción del agente y el cambio en el paciente), el agente lleva a cabo su plan con éxito, el cambio en el paciente es perceptible, el agente vigila el cambio en el paciente a través de la percepción sensorial, hay solo un agente y un paciente específicos (Lakoff y Johnson, 1991). 


\section{2}

Del mismo modo, cuando funciona en la expresión de la consecuencia.

Se trata de construcciones consecutivas sin cuantificador, que tradicionalmente han sido incorporadas al estudio de la coordinación y que en los trabajos más modernos sobre el tema (Álvarez, 1999; Narbona, 2001) no han sido tratadas.

Cuando subían los oradores sudamericanos a la tribuna el público se enfriaba. (Edwards, 1969: 20)

[...] cuando el joven Gide [...] decide entregarse a las letras, la sorpresa de la familia [...] no habría tenido límites. (M. Rojas, 1960: 23)

Cuando nos haya nacido una generación amante de heroísmo en el verdadero sentido de esa palabra, o sea amante de faena costosa y larga, habrá llegado la hora de Alfonso Reyes en América, su meridiano habrá madurado como un fruto. (Mistral, 1978: 33)

Cuando llegue el día en que veamos a la flora que poseemos, al arte rústico que miramos con indiferencia, ornamentar con nuevos y hermosos motivos y sugestiones, nacidos de ellos, a las casas de nuestras ciudades, encontraremos que son bellos nuestra flora y nuestro arte rústico. (Prado, 1981: 57)

La relación entre el tiempo y la consecuencia proviene de la concurrencia de los factores causa y efecto con presencia del contenido temporal. De hecho, según Bartol (1986), ya en la Edad Media los valores consecutivos y temporales se superponían. Narbona (1978: 145) asegura que «la relación temporal está implicada en la correlación consecutiva».

El mismo autor se refiere a las oraciones causal-consecutivas, que se producen por el uso de la forma hasta + por con subordinada en indicativo en español medieval como un tipo oracional «a caballo entre el sentido consecutivo y el causal» (Narbona, 1978: 150).

Fuentes (1985) se refiere a la transposición de valores en un movimiento de lo consecutivo a lo final que no pierde lo consecutivo, como en Una cooperativa de parados ha manifestado numerosas quejas por las dificultades que encuentran para bacer rentable su trabajo, de forma que el producto económico recompense la larga jornada de dedicación ${ }^{4}$. Esta vinculación es reconocida también por Narbona

4 Hemos suprimido algunos fragmentos del ejemplo que lo hacían demasiado extenso para nuestros fines. 
(1978), quien señala que en ocasiones los sentidos consecutivo y final pueden llegar a confundirse, por lo que resulta difícil deslindarlos, como en Viene para que yo lo consuele. En este cruce de sentidos, «la relación cronológica o temporal (no lógica) siempre presente, puede aparecer expresada dentro de la correlación consecutiva» (Narbona, 1978: 154).

Es necesario considerar también la diferencia entre formas que aluden directamente a un tipo determinado de relación temporal y otras, como cuando, que indican el tiempo de manera general, puesto que «su contenido semántico es muy poco preciso, y marca, sin más, un hecho con el que otro coincide en el tiempo» (Marcos Sánchez, 1989: 343). De esta amplitud se desprende el que pueda también usarse en la expresión de la consecuencia, ya que se sitúa en cualquier punto del consecutio temporum.

\section{3}

Por otra parte, en el corpus encontramos cuando en las construcciones condicionales, en su forma de reales. Se trata de fórmulas con las que el hablante expresa contenidos supuestos, de cuyo cumplimiento, en mayor o menor grado, tiene seguridads:

[...] son estilos grotescos cuando se elevan bajo un clima que no los necesita. (Prado, 1981: 34)

Condicionales como la del ejemplo son llamadas de inclusión por Santana (2003: 127), puesto que «expresan la circunstancia que se considera necesaria e imprescindible para que la consecuencia se realice». En un corpus del español de Sevilla encuentra dos nexos en esta relación: siempre que y siempre y cuando, ambos reconocidos como expresiones temporales de las oraciones condicionales por Espinosa (2010). Sabemos, además, formas que expresan tiempo. Notemos también que la autora habla de circunstancia y consecuencia. Podemos pensar que esta circunstancia está tan estrechamente ligada a la ubicación temporal que se requiere la expresión de esa concreción mediante nexos propios de este sentido. Este hecho reafirma nuestro supuesto de la fuerte relación entre la consecutividad y la causalidad.

Rojo y Montero (1983: 30) señalan que «condicionante y condicionado [mantienen] una cierta relación temporal entre sí». La RAE (2009: 1615), indica que «El significado condicional de cuando es compatible con el adverbial en las

5 Aunque solo hemos hallado un ejemplo, el empleo de cuando en oraciones condicionales es frecuente en el español, de acuerdo con lo indicado por Rivarola (1981). 
oraciones generalizadoras» y ejemplifica con Cuando bace frio, bay que prender la calefacción, oración en la que «se habla del momento o del lapso temporal en que debe prenderse la calefacción, pero también de la conveniencia de hacerlo si se da cierta situación» (RAE, 2009: 1615). La explicación que halla la Academia para casos como estos se refiere a la expresión de una cuantificación, pues en el ejemplo que pone, cuando bace frío es equivalente a 'en cada momento o en cada lapso en el que hace frío', de ahí que este traslado del significado temporal al condicional pueda hacerse únicamente con entidades semánticas que puedan cuantificarse. Tal es el caso de nuestro ejemplo. Meana Cubero (2006) reconoce, en su estudio sobre lenguas indoeuropeas, algunos usos en que la conjunción que introduce periodos condicionales se utiliza también para oraciones que implican otro sentido, como el temporal. A su juicio, las oraciones condicionales y temporales se solapan frecuentemente, cruce que se presenta en construcciones que

concretan el escenario en el que tiene lugar lo enunciado en la oración principal, suelen acudir a los mismos modos y tiempos total o parcialmente, tienden a ocupar la misma posición en la frase y en cierta manera establecen una relación semántica análoga entre la oración subordinada y la principal. (Meana Cubero, 2006: 726)

Santana (2003) también observa un proceso de traslación del significado desde la temporalidad a la condicionalidad en mientras (que). En este caso señala:

No resulta extraño que la significación de temporalidad dé paso a una relación de implicación causal entre dos segmentos. La noción de tiempo representa una sucesión cronológica [...] y, en cierto modo, una consecuencia es también un fenómeno que deriva de otro $\mathrm{y}$, en este sentido, debe ser posterior a una causa. (Santana, 2003: 120)

El caso de cuando como forma de expresión de la condición es identificado por Porcar (1993: 43), quien reconoce «la posibilidad de formular oraciones en las que el significado temporal de la proposición introducida por cuando concurre con cierto matiz condicional». Indica también la dificultad de determinar hasta qué punto el objetivo comunicativo primordial es el tiempo en estructuras con cuando + verbo.

Para Polo (1971), toda acción hipotética se produce en el marco espacio temporal, que es, además, el marco de toda expresión lingüística. De ahí, entonces, que estos matices se contagien a lo condicional. Molho (1975) señala que esta relación se genera a partir del desplazamiento del significado 
de cuando, esencialmente temporal, hasta los matices hipotéticos. Del mismo modo, indica que este término concurre con el si condicional porque participan del mismo sistema de conjunciones, por lo que el cuando de posición perfila un $s i$ de suposición «o por lo menos la idea de una hipótesis ligada al tiempo» (Molho, 1975: 528). Porcar (1993: 44) lo explica del siguiente modo:

Cuando designa un momento temporal; enmarca y sitúa la acción verbal de la oración principal en el tiempo. En el terreno de lo no pretérito la acción verbal se erige necesariamente como hipotética y por ello no es posible fijar su posición exacta en el tiempo, únicamente suponerla. En ese sentido cuando realiza un movimiento de retroacción, ocupando en parte el campo de la suposición que domina la conjunción si.

De lo anterior se extrae que cuando y si no son formas idénticas, sino que cuando se orienta hacia si contribuyendo a la vinculación de hipótesis y tiempo en un mismo enunciado (Molho, 1975). El uso de una u otra está en la percepción del hablante respecto a lo dicho. De este modo, indica Porcar (2003), la oración Cuando venga denota mayor seguridad en el cumplimiento de la acción que Si viene.

Santana (2003: 127) señala que en el caso de siempre está contenida una noción de necesidad: «La prótasis es requisito imprescindible en cualquier momento que se quiera realizar el contenido de la apódosis» ${ }^{6}$. Este sentido también está presente en nuestro ejemplo, de lo que surge naturalmente la duda de si la necesidad es una de las características semánticas inherentes a la vinculación de causalidad y temporalidad.

Recordemos que toda causa es indiscutiblemente necesaria para la realización de un efecto, y que con la anulación de uno de los términos de la relación se anula también, y lógicamente, la vinculación: no hay causa sin efecto ni efecto sin causa. En las condicionales, que explicitan el carácter hipotético de la relación causa-efecto, sucede lo mismo: si no se cumple la condición no se cumplirá lo condicionado. Pensamos que esta es una de las características de la vinculación entre la causalidad y la condicionalidad, en donde el cumplimiento de una condición es necesario o indispensable para que se realice lo condicionado.

Por otra parte, Meana Cubero (2006) también indica la existencia del uso compartido de la misma forma para manifestar condición y causa en lenguas indoeuropeas, y lo explica enfatizando en la expresión de la circunstancia

6 El destacado es nuestro. 
contenida en ambas construcciones, característica compartida, también, con las temporales. El autor ha comprobado el uso de las mismas partículas en oraciones finales.

Santana (2003) identifica la vinculación entre causalidad y condicionalidad, puesto que a su juicio se pone de manifiesto una relación causa-consecuencia entre la prótasis y la apódosis. De hecho, ya Bello (1847) define la apódosis como el efecto o consecuencia de la prótasis. Pero, por otro lado, reconocemos que una definición de un campo tan amplio y diverso como el de la condicionalidad no puede agotarse en su delimitación a partir de la causalidad, como señala Rodríguez (2008), pues ello implicaría dejar fuera muchas construcciones que no necesariamente contienen este sentido ${ }^{7}$.

\section{Cuantificación}

\begin{tabular}{|c|c|c|c|c|c|c|c|c|}
\hline Caso/autor & Edwards & Mistral & Neruda & Prado & Rojas G. & Rojas M. & Teitelboim & Total \\
\hline \multicolumn{9}{|l|}{ Conjunciones } \\
\hline cuando & & 3 & 1 & & 1 & 1 & 3 & 9 \\
\hline Otras & 1 & 20 & 15 & 15 & 11 & 13 & 4 & 79 \\
\hline Locuciones & 1 & & & & & & & 1 \\
\hline $\begin{array}{l}\text { Locuciones } \\
\text { adverbiales }\end{array}$ & & 6 & 2 & 1 & 3 & 5 & & 17 \\
\hline Locución modal & & 1 & & & & & & 1 \\
\hline Preposiciones & 10 & 23 & 10 & 7 & 12 & 8 & 13 & 83 \\
\hline $\begin{array}{l}\text { Formas no } \\
\text { finitas }\end{array}$ & & & 1 & 1 & 1 & & & 3 \\
\hline Expresión & & & & & 2 & & & 2 \\
\hline $\begin{array}{l}\text { Oraciones } \\
\text { subordinadas }\end{array}$ & & 1 & & & & & 1 & 2 \\
\hline $\begin{array}{l}\text { Coordinación } \\
\text { copulativa }\end{array}$ & & 1 & & & & & & 1 \\
\hline Yuxtaposición & 6 & 8 & 9 & 2 & & 8 & 3 & 36 \\
\hline Total & 18 & 63 & 38 & 26 & 30 & 35 & 24 & 234 \\
\hline
\end{tabular}

Tabla n. ${ }^{\circ}$ 1: Frecuencia de casos de la causalidad propia

7 Santana (2003), por ejemplo, recuerda que la relación causa-tiempo es aplicable a las condicionales en que la noción de causalidad funciona en el nivel del enunciado, no así a las de la enunciación. 


\begin{tabular}{|l|l|l|l|l|l|l|l|l|}
\hline Caso / autor & Edwards & Mistral & Neruda & Prado & Rojas G. & Rojas M. & Teitelboim & Total \\
\hline Conjunciones & & & & & & & & \\
\hline cuando & 2 & 4 & & 1 & & 1 & 2 & 10 \\
\hline Otras & 3 & 3 & 1 & 10 & 11 & 3 & 5 & 36 \\
\hline Locución modal & & 2 & & 2 & & & 1 & 5 \\
\hline Preposiciones & 3 & 4 & 2 & 13 & 7 & 7 & 1 & 37 \\
\hline Adverbios & & & & 2 & 1 & 3 & 2 & 8 \\
\hline $\begin{array}{l}\text { Formas no } \\
\text { finitas }\end{array}$ & 5 & 3 & 1 & 9 & 1 & 10 & & 29 \\
\hline $\begin{array}{l}\text { Coordinación } \\
\text { copulativa }\end{array}$ & 1 & 6 & 2 & & 2 & 2 & 1 & 14 \\
\hline Yuxtaposición & 1 & 1 & 1 & 1 & 2 & 1 & 2 & 9 \\
\hline Sintagmas & 3 & 2 & & & 2 & 2 & 1 & 10 \\
\hline Concurrencia & & & & 1 & & & & 1 \\
\hline Total & 18 & 25 & 17 & 39 & 26 & 29 & 15 & 159 \\
\hline
\end{tabular}

Tabla n. ${ }^{\text {2 }}$ : Frecuencia de casos de la consecuencia sin cuantificador

\begin{tabular}{|c|c|c|c|c|c|c|c|c|}
\hline Caso/autor & Edwards & Mistral & Neruda & Prado & Rojas G. & Rojas M. & Teitelboim & Total \\
\hline \multicolumn{9}{|l|}{ Reales } \\
\hline cuando & & & & 1 & & & & 1 \\
\hline Otras fórmulas & 2 & 4 & 2 & 4 & 5 & 17 & 2 & 36 \\
\hline Potenciales & & 2 & & & & 2 & & 4 \\
\hline Irreales & 1 & 2 & 1 & & & 1 & & 5 \\
\hline $\begin{array}{l}\text { Construcciones } \\
\text { particulares } \\
\text { con si }\end{array}$ & 2 & 2 & 1 & 1 & 4 & 1 & 3 & 14 \\
\hline Indirectas & & 1 & & 2 & 1 & 1 & & 5 \\
\hline $\begin{array}{l}\text { Prótasis con } \\
\text { formas no finitas }\end{array}$ & 1 & & & & & 3 & & 4 \\
\hline $\begin{array}{l}\text { Conectores } \\
\text { complejos }\end{array}$ & & 2 & & 1 & & 1 & 1 & 5 \\
\hline Otros casos & & & & 2 & 1 & & & 3 \\
\hline $\begin{array}{l}\text { Prótasis con } \\
\text { verbos creadores } \\
\text { de mundo }\end{array}$ & & & & & & 2 & & 2 \\
\hline Total & 6 & 13 & 4 & 11 & 11 & 28 & 6 & 79 \\
\hline
\end{tabular}

Tabla n. ${ }^{\circ}$ 3: Frecuencia de casos de la condición 


\section{Consideraciones finales}

Ante la presencia de las formas temporales que expresan también nociones del campo semántico de la causalidad, reflexionar en torno a la presencia de la vinculación de ambas nociones es una de las perspectivas de estudio ineludible para la lingüística.

Nuestra propuesta se sustenta en las diversas interrogantes que han surgido en los estudios sobre cuando, las oraciones causales y su relación con el eje temporal: ¡Cómo se produce el cruce de sentidos? ¿Es un hecho inmanente del lenguaje u obedece a factores ajenos a él? Como Bartol (1988), pensamos que la búsqueda de respuestas, tanto en factores internos como en otros externos, puede conducirnos a la explicación del proceso de cambio. Sin embargo, aún queda por aclarar los motivos que facilitan la vinculación, ya sea en la forma latina inicial, ya sea en el español actual.

La causalidad y la temporalidad exigen la presencia de al menos dos puntos de referencia: una causa y en efecto, un punto en el eje temporal desde el cual medirlo. Así, las acciones causativas se realizan efectivamente (para el hablante) en ese eje temporal: (repetimos) toda causa es anterior a su consecuencia. Y con anterior lo que se expresa es que toda causa tiene una dimensión temporal en la cual se realiza. Esta relación tiene una presencia tan frecuente e importante en nuestra vida (como indican Lakoff y Johnson, 1991), que ha impregnado los ámbitos de la causalidad que hemos definido desde una perspectiva semánticamente amplia y que en el corpus se manifiesta en oraciones causales, consecutivas y condicionales.

Esta noción alcanza una manifestación lingüística, debido a que el lenguaje es lineal, y así como un signo es posterior a otro, la consecuencia es posterior a la causa. Producida esta vinculación, la lengua española ha echado mano de algunas formas, como cuando, que pese a su descripcion gramatical tradicional como forma temporal, se usa para la expresión de la causalidad, pues, como hemos dicho, lo hechos se suceden en el tiempo, pero no sólo a propósito del paso del tiempo, sino que, en muchísimos casos, por causas (efectivas o no) que inciden en su realización. De ahí la vinculación entre temporalidad y causalidad, y de ahí también la expresión de esta última en una multitud de matices que enriquecen nuestra lengua. 


\section{Bibliografía}

Alarcos, E. (1999): Gramática de la lengua española. Madrid: Espasa Calpe.

Álvarez, A. (1999): «Las construcciones consecutivas». En: Ignacio Bosque, Violeta Demonte (dirs.), Gramática descriptiva de la lengua española, III. Madrid: Espasa Calpe, 3739-3804.

Bartol Hernández, J. A. (1988): Las oraciones causales en la Edad Media. Madrid: Paraninfo.

Bassols de Climent, M. (1981): Sintaxis latina 2. Madrid: CSIC.

Bello, A. (1847): Gramática de la lengua castellana, destinada al uso de los americanos. Santiago de Chile: Imprenta del Progreso.

Cancino Cabello, N. (2006): «Contraste y causalidad en las expresiones adversativas excluyentes. Análisis de un corpus ensayístico del español». En: Nueva Revista del Pacífico, 51, 11-19.

Corominas, J. (1954): Diccionario crítico etimológico de la lengua castellana, II. Madrid: Gredos.

Cuervo, R. J. (1992-1994): Diccionario de construcción y régimen de la lengua castellana. Bogotá: Instituto Caro y Cuervo.

Del Campo, M. E. (1998): Las construcciones causales en español. Oviedo: Universidad de Oviedo.

DRAE: Real Academia Española (2001): Diccionario de la Lengua Española, I. Madrid: Espasa Calpe.

Espinosa Elorza, R. M. (2010): Procesos de formación y cambio en las llamadas «palabras gramaticales». San Millán de la Cogolla: CiLengua.

Flamenco García, L. (1999): «Las construcciones adversativas y concesivas». En: Ignacio Bosque, Violeta Demonte (dirs.), Gramática descriptiva de la lengua española, III. Madrid: Espasa Calpe, 3805-3878.

Fuentes Rodríguez, C. (1985): Sintaxis oracional (Las oraciones consecutivas en español). Sevilla: Alfar.

Galán, C. (1999): «La subordinación causal y final». En: Ignacio Bosque, Violeta Demonte (dirs.), Gramática descriptiva de la lengua española. III. Madrid: Espasa Calpe, 3597-3642.

Gili Gaya, S. (1970): Curso Superior de Sintaxis Española. Barcelona: Bibliograf. 
Goethals, P. (2002): Las conjunciones causales explicativas españolas 'como', 'ya que', 'pues' y 'porque’. Un estudio semiótico-lingüístico. Leuven-París-Dudley: Peeters.

Hue Fanost, C. (1986): Estudio sincrónico del adverbio: análisis constrastivo entre el español y el francés, III. Madrid: Editorial de la Universidad Complutense de Madrid.

Hue Fanost, C. (1987): El adverbio. Madrid: Sociedad General Española de Librería.

Lakoff, G., Johnson, M. (1991): Metáforas de la vida cotidiana. Madrid: Cátedra.

Marcos Marín, F. (1979): «A propósito de las oraciones causales. Observaciones críticas». En: Cuadernos de Filología. Stvdia lingvistica bispanica, II, 1. Valencia: Facultad de Filología, Universidad de Valencia, 163-171.

Marcos Sánchez, M. M. (1989): «Oraciones temporales en el español antiguo: relaciones de simultaneidad». En: Julio Borrego Nieto, José Jesús Gómez Asencio, Luis Santos Río (eds.), Pbilologica II. Homenaje a D. Antonio Llorente. Salamanca: Universidad de Salamanca.

Meana Cubero, S. (2006): Análisis comparativo de los períodos condicionales en las lenguas indoeuropeas. Tesis Doctoral. Sevilla: Universidad de Sevilla.

Menéndez Pidal, R. ([1908] 1944): Cantar de Mio Cid. Texto, gramática y vocabulario, I. Madrid: Espasa-Calpe.

Meyer-Lübke, W. (1972): Romanisches Etymologisches Wörterbuch. Heidelberg: Carl Winter.

Molho, M. (1975): Sistemática del verbo español (aspectos, modos y tiempos), I y II. Madrid: Gredos.

Montolío, E. (1999): Las construcciones condicionales. En: Ignacio Bosque, Violeta Demonte (dirs.), Gramática descriptiva de la lengua española, III. Madrid: Espasa Calpe, 3641-3737.

Montolío, E. (2001): Conectores de la lengua escrita. Contraargumentativos, consecutivos, aditivos y organizadores de la información. Barcelona: Ariel.

Mosteiro Louzao, M. (1999): Las conjunciones de causa en castellano medieval. Santiago de Compostela: Universidade de Santiago de Compostela.

Mosteiro Louzao, M. (2001): Los esquemas causales en castellano medieval. Santiago de Compostela: Universidade de Santiago de Compostela. 
Narbona, A. (1978): Las proposiciones consecutivas en español medieval. Granada: Universidad de Granada, Secretariado de Publicaciones.

Narbona, A. (1989a): «Finales y finalidad». En: Sintaxis española: nuevos y viejos enfoques. Barcelona: Ariel, 137-145.

Narbona, A. (1989b): Las subordinadas adverbiales en español. Bases para su estudio. Málaga: Librería Ágora.

Narbona, A. (1989c): «Sobre las oraciones bipolares». En: Sintaxis española: nuevos y viejos enfoques. Barcelona: Ariel, 125-136.

Narbona, A. (1990): Las subordinadas adverbiales en español II. Causales y finales, comparativas y consecutivas, condicionales y concesivas. Málaga: Librería Ágora.

Narbona, A. (2001): «Otra vez sobre interordinación y subordinación». En: Elena Méndez, Josefa Mendoza, Yolanda Congosto (eds.), Indagaciones sobre la lengua. Sevilla: Universidad de Sevilla, 119-137.

Polo, J. (1971): Las oraciones condicionales. Ensayo de teoría gramatical. Granada: CSIC, Universidad de Granada.

Porcar Miralles, M. (1993): La oración condicional. La evolución de los esquemas verbales condicionales desde el latín al español actual. Castelló: Universitat Jaume I.

Real Academia Española ([1973] 1985): Esbozo para una nueva gramática de la lengua española. Madrid: Espasa Calpe.

Real Academia Española (2009): Nueva gramática de la lengua española, I y II. Madrid: Espasa.

Ridruejo, E. (1981): «Como + subjuntivo con sentido causal». En: Horst Geckeler, Brigitte Schlieben-Lange, Jürgen Trabant, Harald Weydt (eds.), Logos Semantikos. Studia in Honorem E. Coseriu, IV. Madrid: Gredos, 315-326.

Rivarola, J. L. (1976): Las conjunciones concesivas en español medieval y clásico. Contribución a la sintaxis bistórica española. Tubinga: Max Niemeyer.

Rodríguez Rosique, S. (2008): Pragmática y gramática. Condicionales concesivas en español. Fráncfort del Meno: Peter Lang.

Rojo, G. (1990): «Relaciones entre temporalidad y aspecto en el verbo español». En: Ignacio Bosque (ed.), Tiempo y aspecto en español. Madrid: Cátedra, 17-43. 
Rojo, G., Montero, E. (1983): La evolución de los esquemas condicionales (Potenciales e irreales desde el poema del Cid hasta el 1400). Santiago de Compostela: Universidade de Santiago de Compostela.

Santana Marrero, J. (2003): Las oraciones condicionales: Estudio en la lengua bablada. Sevilla: Universidad de Sevilla.

\section{Corpus}

Edwards Bello, J. (1969): En torno al periodismo y otros asuntos. Santiago de Chile: Andrés Bello, 13-30.

Mistral, G. (1978): Recados para América. Santiago de Chile: Revista Pluma y Pincel / Instituto de Ciencias Alejandro Lipschutz, 11-39.

Neruda, P. (2000): Prólogos. Santiago de Chile: Sudamericana, 89-96, 98-99, 103-104.

Prado, P. (1981): Ensayos sobre arquitectura y poesía. S/1: Nascimento, 21-51.

Rojas, G. (1998): América es la casa. Salamanca: Centro de Estudios Ibéricos y Americanos, 11-25.

Rojas, M. (1960): El árbol siempre verde. Santiago de Chile: Zig-Zag, 11-26.

Teitelboim, V. (1969): Hombre y hombre. Santiago de Chile: Austral, 21-37. 
Nataly Cancino Cabello

University of Sevilla

\section{Causality and temporality: the case of cuando (when) in XX century Chilean essays}

Keywords: causality, consecutivity, conditionality, temporality, essays

This study analyzes expression of causality in a corpus of essays by $20^{\text {th }}$ century Chilean authors. After a review of the theoretical literature, we concluded that there are different theoretical proposals for the treatment of the relationship between cause and effect. This decision was reached because, aside from its formal and functional expression in language, causality consists of a logical and semantic relationship inherent to natural processes, in that cause always precedes effect. For this reason, the cause-effect relationship is not exclusive to causal relationships, but it also encompasses other types of structures in which the degree or type of relationship/bonding among the parts of the construction will vary. For this reason, in this research we have considered all constructions where causal relationships are manifested in some respect: causal, consecutive, final, concessive and conditional. We can also add to this some cases of exclusive opposites in which appears to be an explanatory relationship. With this assumption in mind, we focus on the explanation of the synchronic use of cuando (when) in temporal expressions. From this analysis some concerns have arisen that cannot be explained by the actual use of the form in question. Therefore, we must look for the answers in the aspects of linguistic change that gave rise to it. In addition, a quantification of the results shows the frequency of cuando (when) as compared to other forms of causal relationship that are not related to temporality. 
Nataly Cancino Cabello

Univerza v Sevilli

\section{Vzročnost in časovnost: primer cuando (kadar, ko) v čilskih esejih 20. stoletja}

Ključne besede: vzročnost, posledičnost, pogojnost, časovnost, eseji

V pričujoči študiji avtorica analizira izražanje vzročnosti v korpusu, ki ga tvorijo eseji čilskih avtorjev 20. stoletja, in ugotavlja, da obstaja več teoretičnih pristopov pri obravnavi povezav vzroka (vzrokov) in njegovih (njihovih) posledic. Izbrala je širok semantični pristop, ker ima vzročnost poleg formalnega in funkcionalnega izražanja $\mathrm{v}$ jeziku tudi inherentno logično in semantično povezavo $\mathrm{z}$ naravnimi procesi ter se zato navezuje na časovnost, kajti vzrok je vedno pred posledico. Iz tega se da sklepati, da se odnos vzrok - posledica ne pojavlja zgolj v vzročnih relacijah, ampak tudi pri drugih strukturah, pri katerih je stopnja ali vrsta povezave med enotami različna. Pri tej raziskavi upošteva vse strukture, kjer se pojavlja vzročnost: vzročne, posledične, namenske, dopustne in pogojne. $\mathrm{K}$ njim prišteva tudi nekatere protivne izključitvene oblike, kjer je prisoten razlagalni odnos. Izhajajoč iz te domneve se osredotoči na sinhrono rabo cuando (ko, kadar), ki se rabi za izražanje časovnosti. Iz analize izhajajo določene nejasnosti, ki jih ne moremo razložiti s sodobno rabo te oblike, zato je treba iskati odgovore v jezikovnem spreminjanju. Po drugi strani pa štetje rezultatov kaže na pogostost rabe cuando v primerjavi z drugimi oblikami, ki izražajo vzročnost, a niso povezane $s$ časovnostjo. 